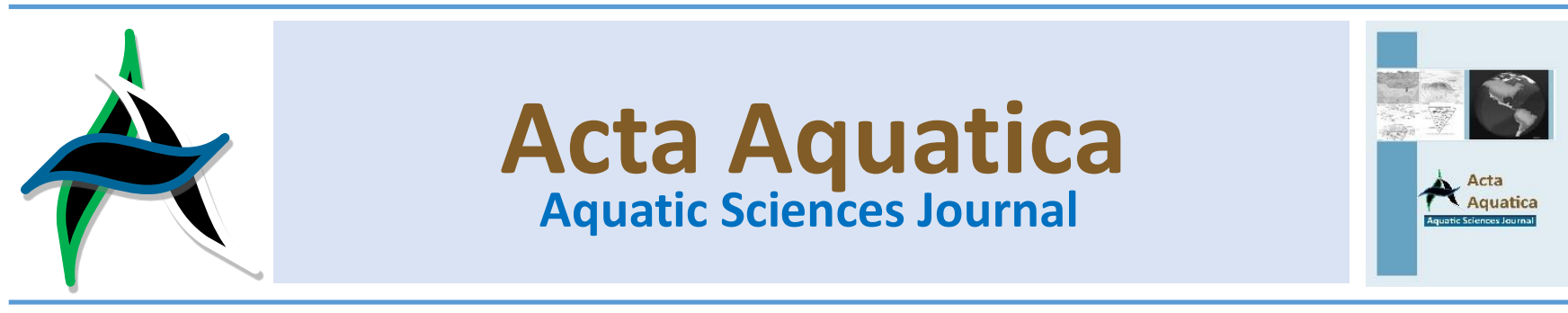

\title{
Tingkat efektifitas pemberian bantuan dana pengembangan usaha mina pedesaan (PUMP) pada kelompok nelayan di Kota Banda Aceh
}

\section{The level of grant effectiveness for Mina Rural Business Development Program (PUMP) on fishermen group in Banda Aceh}

\author{
Elfa Yeni ${ }^{a, *}$ dan Agus Naufal ${ }^{a}$ \\ a Program Studi Pemanfaatan Sumverdaya Perikanan, Fakultas Perikanan, Universitas Abulyatama
}

\begin{abstract}
Abstrak
Program Pengembangan Usaha Mina Pedesaan (PUMP) merupakan program yang dibuat oleh Departemen Kelautan dan Perikanan sebagai salah satu upaya untuk menanggulangi masalah kemiskinan pada masyarakat pesisir. Saat ini program PUMP di kota Banda Aceh sudah berjalan tetapi dalam kenyataannya masih banyak masyakat pesisir terutama para nelayan yang belum mendapat manfaat dari program tersebut. Tujuan penelitian ini adalah untuk mengetahui tingkat efektivitas bantuan PUMP dan mengetahui manfaat-manfaat dari dari program PUMP pada kelompok nelayan di Kota Banda Aceh. Metode pengambilan data adalah dengan metode survey pada 8 kelompok nelayan yang ada di kecamatan Syah Kuala Kota Banda Aceh. Dari data yang diperoleh diketahui bahwa tingkat pemberian bantuan dana PUMP pada kelompok nelayan adalah $43 \%$ dinilai tidak efektif. Hal ini disebabkan oleh kurangnya pembinaan dan pendampingan terhadap kelompok nelayan yang memerima bantuan dana PUMP.
\end{abstract}

\begin{abstract}
Mina Rural Business Development Program (PUMP) is a program created by the Ministry of Marine Affairs and Fisheries as an effort to tackle the problem of poverty in coastal communities. Currently PUMP program in Banda Aceh has been running but, there are still many coastal communities especially fishermen who have not benefited from the program yet. The purpose of this research is to know the level of effectiveness of PUMP assistance and the benefits of PUMP program on fishermen group in Banda Aceh. Survey method was applied by dividing 8 groups of fishermen in Syiah Kuala sub-district of Banda Aceh. As a result, $43 \%$ of PUMP funding level was ineffective for fishermen group. It was caused by the lack of guidance and assistance to the fishermen group who receive PUMP funding assistance.
\end{abstract}

Keywords: effectiveness; poverty; fishermen; PUMP

\section{Pendahuluan}

Bagi masyarakat pesisir kota Banda Aceh, mata pencaharian utama adalah nelayan tradisional. Kehidupan sosial ekonomi nelayan tradisional ini masih memiliki ketergantungan dengan hasil tangkapan ikan dengan peralatan seadanya. Kondisi ini tentu akan mempengaruhi produktivitas hasil tangkapan. Keterbatasan hasil tangkapan tentu akan berdampak terhadap pemenuhan ekonomi keluarga. Keterbatasan ini menyebabkan nelayan tardisional sangat rentan dengan kemiskinan.

\footnotetext{
* Korespondensi: Program Studi Pemanfaatan Sumberdaya Perikanan Fakultas Perikanan. Universitas Abulyatama. Jalan Blang Bintang Lama Km. 8,5 Lampoh Keudee, Aceh Besar. Provinsi Aceh, Indonesia. e-mail: elfayeni007@gmail.com doi: https://doi.org/10.29103/aa.v5i2.776
}

Menghadapi problematika masyarakat pesisir tersebut, pemerintah melalui Departemen Kelautan dan Perikanan telah membentuk program pemberdayaan social untuk meningkatkan kesejahteraan masyarakat pesisir. yaitu Program Pengembangan Mina Usaha Pedesaan (PUMP) yang dikhususkan untuk masyarakat pesisir (KKP, 2014). Program ini berjalan dengan dana yang berasal dari APBN dan dana kompensasi BBM serta dukungan penuh dari Departemen Kelautan dan Perikananan. Sekarang program PUMP telah dilaksanakan di 247 Kabupaten/Kota. Program PUMP diadakan untuk memberdayakan masyarakat pesisir sekaligus mengatasi dampak kenaikan harga Bahan Bakar Minyak (BBM) terhadap perekonomian masyarakat pesisir, yang difokuskan pada penguatan modal melalui perguliran Dana Bantuan Langsung Masyarakat (BLM). Pada saat ini Program PUMP sudah berjalan di Banda Aceh tetapi masih banyak masyakat pesisir terutama para nelayan yang belum mendapat manfaat dari program 
tersebut. Hal ini perlu dilakukan penelitian untuk melihat sejauhmana tingkat Efetivitas Pemberian Dana Bantuan PUMP Pada Kelompok Nelayan di Kota Banda Aceh.

\section{Bahan dan metode}

\subsection{Waktu dan tempat}

Penelitian ini dilaksanakan di Kecamatan Syiah Kuala, yaitu di Desa Alue Naga dan Desa Deah Raya kecamatan Syah Kuala kota Banda Aceh. Waktu penelitian ini di mulai bulan April 2017 hingga Agustus 2017.

\subsection{Materi penelitian}

Metode yang digunakan dalam penelitian ini adalah metode survey, yaitu melakukan pengamatan langsung $d i$ lapangan guna mendapatkan gambaran yang jelas tentang keefektifan dan manfaat yang didapat oleh kelompok nelayan yang telah diberi bantuan dana PUMP oleh Dinas Kelautan Perikanan.

\subsection{Metode pengembilan sampel}

Pengambilan data dilakukan secara acak sederhana (simple random sampling). Jumlah sampel yang diambil adalah 35 orang anggota kelompok dari 8 kelompok nelayan yang ada di Desa Alue Naga dan Desa Deah

\subsection{Pengumpulan data}

Data yang dikumpulkan adalah data primer dan data sekunder. Data primer dikumpulkan melalui wawancara yang berpedoman dengan kuisioner yang telah dipersiapkan terlebih dahulu. Data ini meliputi data kelompok nelayan, data bantuan yang diterima oleh masing-masing kelompok nelayan dan data lain yang dirasa perlu. Data sekunder dikumpulkan dari dinas Perikanan Kelautan perikanan Provinsi Aceh dan Badan Pusat Statistik Provinsi Aceh

\subsection{Analisis data}

Analisa data dilakukan dengan analisa data Deskriptif, Kualitatif yaitu berupa uraian terperinci berisi penggambaran pola-pola klasifikasi/kategorisasi untuk mempertimbangkan tanggapan/pandangan atau opini/tanggapan informan, maupun hasil pengamatan peneliti di lapangan. Untuk mengukur tingkat efektivitas, digunakan Indikator penilaian variabel (Tabel 1).

Tabel 1.

Variabel indicator evaluasi

\begin{tabular}{|c|c|c|}
\hline Number & Indicator & Value \\
\hline 1 & Efektif & (3) \\
\hline 2 & Kurang efektif & (2) \\
\hline 3 & Tidak efektif & (1) \\
\hline
\end{tabular}

Skor $=\frac{[(\mathrm{F} 1 \mathrm{XBN} 1)}{\mathrm{N}}+\frac{(\mathrm{F} 2 \mathrm{XBN} 2)}{\mathrm{N}}+\frac{(\mathrm{F} 3 \mathrm{XBN} 3)]}{}$

Keterangan:

$\mathrm{F} 1, \mathrm{~F} 2, \mathrm{F3}=$ Frekuensi

B1, B2, B3 = Bobot Nilai

$$
\mathrm{N} \quad=\text { Jumlah Responden }
$$

Ordinal yang dimiliki kemudian diubah menjadi data interval, dengan cara mencari rata- rata skor setiap item (indikator terukur) dari variable independen dan dependen (angka mutlak maupun persentase), dalam klasifikasi:

$\begin{array}{lll}\text { Efektif } & : \quad \begin{array}{l}\text { Apabila skor rata-rata dari indikator }(2-<3) \\ \text { atau } 60 \%<100 \%\end{array} \\ \text { Kurang Efektif }: \begin{array}{l}\text { Apabila skor rata-rata dari indikator }(1-2) \\ \text { atau } 20 \%<60 \%\end{array} \\ \text { Tidak Efektif }: \begin{array}{l}\text { Apabila skor rata-rata dari indikator }(<1) \\ \text { atau }<20 \%\end{array}\end{array}$

\section{Hasil dan pembahasan}

\subsection{Hasil}

\subsubsection{Kondisi umum daerah penelitian}

Kota Kota Banda Aceh terletak antara $0516^{\prime} 15^{\prime \prime}-0536^{\prime \prime}$ 16" LU dan 95 16' 15" - 95 22' 35" BT Luas wilayah administratif Kota Banda Aceh sebesar $61.359 \mathrm{Ha}$ atau kisaran $61.36 \mathrm{Km}^{2}$. Syiah Kuala adalah salah satu kecamatan di Kota Banda Aceh. Kelurahan/desa di Kecamatan Syiah Kuala adalah le Masen Kaye Adang, Pineung, Lamgugob, Kopelma Darussalam, Rukoh, Jeulingke, Tibang, Deah Raya, Alue Naga, Peurada dengan jumlah penduduk 35.671 jiwa (BPS, 2013).

\subsubsection{Kondisi penduduk}

Kondisi sosial ekonomi masyarakat Kecamatan Syah Kuala sebagian besar bermata pencaharian sebagai nelayan. Selain itu, ada juga peternak, buruh, pedegang/wiraswasta dan petani. Keadaan ekonomi penduduk Kecamatan Syah Kuala dapat dilihat menurut pekerjaan. Lebih jelasnya pada tabel 2 berikut ini.

Tabel 2.

Status pekerjaan penduduk

\begin{tabular}{clc}
\hline No & \multicolumn{1}{c}{ Pekerjaan } & Jumlah \\
\hline 1. & Tidak bekerja & - \\
2. & Buruh & 15 \\
3. & Wirausaha & 20 \\
4. & FNelayan & 70 \\
5. & PNS / ABRI / Pensiunan & 15 \\
6. & Swasta & 25 \\
7. & Petani & 30 \\
\hline Sunber, BPS, 2013
\end{tabular}

\subsubsection{Karakteristik responden}

Umur merupakan salah satu faktor yang penting dalam menunjang suatu kegiatan yang dilakukan. Berdasarkan hasil dari penelitian penulis Umur responden yang penulis kalkulasikan adalah sebagai berikut (tabel 3).

Tabel 3.

Status pekerjaan

\begin{tabular}{cccc}
\hline No & Umur & Jumlah & Persentase \\
\hline 1. & $20-27$ & 6 & $17 \%$ \\
2. & $28-40$ & 13 & $37 \%$ \\
3. & $41-50$ & 10 & $29 \%$ \\
4. & $51-60$ & 4 & $11 \%$ \\
\hline
\end{tabular}

\subsubsection{Mekanisme bantuan}

Mekanisme penyaluran bantuan (Gambar 1) adalah sebagai berikut: 
1. Kelompok masyarakat menyampaikan usulan proposal kegiatan dan besaran Bantuan Langsung Masyarakat (BLM) sesuai dengan yang tercantum dalam dokumen perencanaan kepada Tim Pemberdayaan Masyarakat (Tim PM) yang telah ditetapkan oleh Dinas Kota Banda Aceh

2. Tim PM melakukan identifikasi, verifikasi dan seleksi terhadap usulan proposal calon penerima Bantuan Langsung Masyarakat (BLM) sesuai dengan kriteria yang berlaku kepada Ketua Pengguna Anggaran (KPA) dalam hal ini Kepala Dinas Kelautan dan Perikanan Kota Banda Aceh

3. Dinas Kelautan dan Perikanan Kota Banda Aceh menetapkan penerima Bantuan Langsung Masyarakat (BLM) yang telah diajukan oleh Tim PM

4. Tim PM mensosialisasikan hasil penetapan penerima BLM kepada kelompok masyarakat.

5. Penerima Bantuan Langsung Masyarakat (BLM) membuka rekening atas nama kelompok masyarakat ke bank Pelaksana dilampiri 3 (tiga) spesimen tanda tangan yang terdiri atas ketua, sekertaris, dan bendahara.

6. Dinas kelautan dan Perikanan Kota Banda Aceh mengusulkan penerima dana BLM ke KPPN.

7. KPPN mencairkan dana BLM ke rekening penerima. Proses penyaluran Bantuan Langsung Masyarakat

Pengajuan proposal bantuan PUMP dari kelompok nelayan ke Dinas Kelautan Perikanan dapat dilihat pada table dibawah ini.

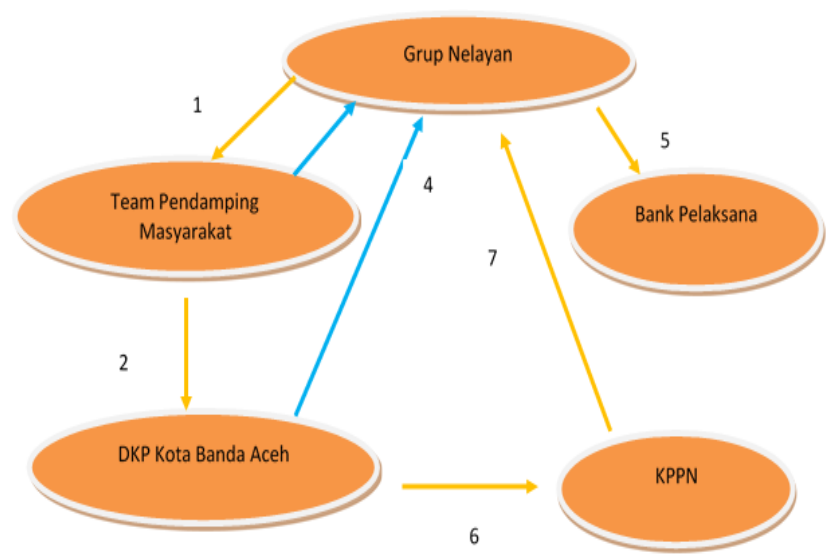

Gambar 1. Mekanisme penyaluran pemberian dana bantuan

Pengajuan proposal bantuan PUMP dari kelompok nelayan ke Dinas Kelautan Perikanan dapat dilihat pada tabel 4.

Tabel 4.

Efektifitas proposal PUPM yang diusulkan oleh kelompok nelayan

\begin{tabular}{lcccc}
\hline \multicolumn{1}{c}{ Ketegori } & Skor & Frekuensi & Nilai & Deskripsi \\
\hline Efektif & 3 & 31 & 93 & \\
Kurang efektif & 2 & 4 & 8 & \\
Tidak efektif & 1 & 0 & 0 & \\
Hasil & & 35 & 101 & \\
Rata-rata & & & & Efektif \\
\hline
\end{tabular}

Nilai yang didapat dari pengajuan proposal bantuan PUMP oleh nelayan adalah $92 \%$ yang berarti sangat efektif. Tingginya persentase ini di sebabkan proses pengajuan proposal memenuhi persyaratan yang telah dibuat dan hanya beberapa proposal yang tidak memenuhi persyarata dana bantuan PUMP. Untuk nilai efektifitas pemberian bantuan terhadap pengajuan proposal dana PUMP yang diajukan oleh kelompok nelayan dapat dilihat pada tabel 5 .
Tabel 5.

efektifitas pemberian bantuan terhadap pengajuan proposal dana PUMP

\begin{tabular}{lcccc}
\hline \multicolumn{1}{c}{ Ketegori } & Skor & Frekuensi & Nilai & Deskripsi \\
\hline Efektif & 3 & 10 & 30 & \\
Kurang efektif & 2 & 14 & 28 & \\
Tidak efektif & 1 & 11 & 11 & \\
Hasil & & 35 & 69 & Kurang efektif \\
Rata-rata & & 1.97 & & \\
\hline
\end{tabular}

Tingkat efektivitas pemberian bantuan terhadap jumlah kelompok nelayan adalah kurang efektif. Hal ini dapat dilihat dari persentase efektivitas pemberian bantuan terhadap jumlah kelompok nelayan yang dibawah $60 \%$ dan nilai rata-rata yang dibawah 2 tetapi di atas 1, menunjukkan bahwa ada beberapa kelompok nelayan yang belum mendapatkan bantuan. Artinya tingkat efektivitas pemberian bantuan terhadap jumlah penerima bantuan masih kurang efektif.

Untuk tingkat efektifitas pemberian bantuan PUMP terhadap kelompok nelayan dapat dilihat pada tabel di bawah ini.

Tabel 6.

Efektivitas Pemberian Bantuan PUMP terhadap Kelompok Nelayan

\begin{tabular}{lcccc}
\hline \multicolumn{1}{c}{ Ketegori } & Skor & Frekuensi & Nilai & Deskripsi \\
\hline Efektif & 3 & 11 & 33 & \\
Kurang efektif & 2 & 16 & 32 & \\
Tidak efektif & 1 & 8 & 8 & \\
Hasil & & 35 & 73 & Kurang efektif \\
Rata-rata & & 2 & & \\
\hline
\end{tabular}

Nilai rata-rata efektivitas bantuan PUMP terhadap kelompok nelayan adalah kurang efektif. Karena nilai persentase kategori efektif berada dibawah $60 \%$ yaitu $45 \%$ maka dikategorikan kurang efektif.

\subsection{Pembahasan}

Pada umumnya masyarakat pesisir yang berprofesi sebagai nelayan tidak cukup mengenyam pendidikan yang tinggi, rata-rata tingkat pendidikan nelayan tersebut paling tinggi adalah tamatan SMA sederajat, hanya sedikit yang tamatan sarjana. Pendidikan mempengaruhi nelayan dalam mengadopsi tehnologi dan keterampilan manajemen untuk mengelola usahanya. Semakin tinggi tingkat pendidikan diharapkan pola pikir semakin rasional, sehingga nelayan lebih mudah untuk menerima teknologi baru dalam upaya meningkatkan hasil tangkapan. Sebagai suatu sistem, masyarakat nelayan terdiri atas kategori-kategori sosial yang membentuk kekuatan sosial. Mereka juga memilki sistem nilai dan simbol-simbol kebudayaan sebagai referensi perilaku mereka sehari-hari. Faktor budaya ini menjadi pembeda masyarakat dari kelompok nelayan lainnya. Sebagian besar masyarakat pesisir, baik langsung maupun tidak langsung mengantungkan kelangsungan hidupnya dari mengelola mengantungkan kelangsungan hidupnya dari mengelola potensi sumberdaya perikanan (Kusnadi, 2009).

Pelaksanaan program BLM-PUMP di Kecamatan Syah Kuala khususnya Desa Alue Naga dan Desa Deah raya Naga dimulai dari penentuan lokasi atau tempat dilaksanakannya program, dan telah dilaksanakan sesuai kriteria dan prosedur. Desa Alue Naga dan Desa Deah Raya merupakan daerah yang termasuk lokasi minapolitan berbasis perikanan tangkap yang telah membentuk Kelompok Usaha Bersama (KUB) di Dinas Kabupaten/Kota, Provinsi. 
Tingginya tingkat efektivitas pengajuan proposal bantuan PUMP oleh kelompok nelayan yaitu 92\% menunjukkan adanya upaya dari masyarakat nelayan untuk memperbaiki taraf kehidupan mereka. Dua hal utama yang terkandung dalam kemiskinan, maupun kerentanan dan ketidak berdayaan (Mulyadi, 2007). Dengan kerentanan yang dialami, orang miskin akan mengalami kesulitan untuk menghadapi situasi darurat.

Upaya masyarakat dalam meningkatkan taraf hidup mereka ternyata tidak diiringi dengan pengetahuan yang cukup dalam pembuatan proposal tersebut sehingga tidak banyak proposal yang lolos dalam proses pengajuannya kepada Dinas Kelautan Perikanan. Hal ini terlihat dari rendahnya tingkat efektivitas pemberian bantuan PUMP terhadap pengajuan proposal. Salah satu sebabnya adalah karena kurangnya pendampingan dan informasi dari pendamping kepada masyarakat

Rendahnya tingkat efektifitas pemberian bantuan dana PUMP kepada nelayan disebabkan oleh beberapa hal. Yang pertama adalah karena kurangnya informasi dan pemahaman anggota KUB terhadap kegunaan dana PUMP tersebut sehingga masyarakat tidak menggunakan dana tersebut secara bijaksana. Yang kedua adalah kurangnya pembekalan kepada pengelola KUB pasca penyaluran bantuan. Sehingga pengelolaan dana tidak terkoordinir dengan baik.

\section{Kesimpulan}

kesimpulan:

Dari penelitian yang telah dilakukan terdapat beberapa

1. Tingkat efektifitas pengajuan proposal bantuan dana PUMN oleh KUB kepada Dinas Kelautan Perikanan adalah efektif.

2. Tingkat efektifitas pemberian efektifitas pemberian bantuan dana PUMP terhadap pengajuan proposan oleh KUB adalah tidak efektif.

3. Tingkat efektifitas pemberian bantuan dana PUMP kepada KUB adalah tidak efektif.

\section{Ucapan penghargaan}

Ucapan terima kasih kepada Kemenristek Dikti yang telah mendanai penelitian ini pada skema Penelitian Dosen Pemula (PDP) tahun 2016.

\section{Bibliografi}

Badan Pusat Statistik Banda Aceh, 2013. Aceh Dalam Angka Tahun 2013. BPS Banda Aceh.

Imran, M., 2003. Kemiskinan dalam Masyarakat Nelayan. Jurnal Masyarakat dan Budaya. Pusat Penelitian Kemasyarakatan dan Kebudayaan LIPI. Jakarta.

Kementrian Kelautan dan Perikanan (KKP), 2014. Pedoman Teknis Pelaksanaan Kegiatan Pengembangan Usaha Mina Perdesaan Bidang Perikanan Tangkap Nomor KEP. 32/KEP-DJPT/2014.

Kusnadi, 2009. Keberdayaan Nelayan dan Dinamika Ekonomi Pesisir. Pusat Penelitian Wilayah Pesisir Dan Pulau-Pulau Kecil. Jember: Lembaga Penelitian Universitas Jember.

Muhidin, S.A., 2009. Konsep Efektivitas Pembelajaran. (online).http://sambasalim.com/pendidik an/konsep-efektivitas-pembelajaran.html. (diakses oktober 2017).

Mulyadi S., 2007. Ekonomi Kelautan. Jakarta: PT Raja Grafindo Persada. $148 \mathrm{hlm}$ 